\title{
Análise de erros experimentais em práticas de laboratório
}

\author{
Mota, M. V. C. ${ }^{1}$; Vieira, F. T. ${ }^{2}$
}

1 - Graduando em Engenharia Química, Universidade Federal Do Espírito Santo, Alegre, ES, Brasil.

2 - Departamento de Engenharia Rural, Universidade Federal do Espírito Santo, Alegre, ES, Brasil.

\begin{abstract}
Resumo
A estatística é um conjunto de técnicas apropriadas para coletar, classificar e apresentar um grupo de dados numéricos. No ambiente acadêmico, ela é utilizada para a análise de dados experimentais, possibilitando a caracterização da qualidade dos dados coletados em atividades de pesquisa e práticas de laboratório. Este artigo teve como principal objetivo o aprendizado sobre a utilização de ferramentas estatísticas para análise de dados em práticas laboratoriais. Foram realizadas diversas práticas laboratoriais com auxílio de cinco voluntários de uma escola local. Todas as práticas foram realizadas em réplicas por esses cinco alunos a fim de avaliar os erros experimentais.
\end{abstract}

Palavras-chave: estatística, erro experimental, práticas laboratoriais.

\section{Introdução}

A estatística é definida como um conjunto de métodos e técnicas que envolvem todas as etapas de uma pesquisa. Ela processa conjuntos de dados para a quantificação da quantidade de incerteza existente na resposta para um determinado problema [1]. De fato, a estatística tem sido utilizada em diversas áreas com intuito de otimizar recursos econômicos, aumentar a qualidade e produtividade e melhorar a análise de decisões com o menor risco possível.

Nesse sentido, esse trabalho utiliza dois testes estatísticos: o teste t de Student, proposto por William Sealy Gosset em 1908, tem como finalidade aceitar ou rejeitar a hipótese de igualdade entre duas amostras de dados ou entre uma amostra e um único valor dito como correto. Já o teste $\mathrm{F}$ proposto por Ronald Fisher compara estritamente variância entre amostras. [2]

\section{Experimento I}

O objetivo deste primeiro experimento foi observar se erros observacionais afetariam a estimativa da densidade calculada para o fluido desconhecido utilizando os conceitos de estática dos fluidos.
É possível calcular a densidade do líquido desconhecido fazendo somatório das pressões em ambos lados do tubo e depois igualando os pontos P1 e P2 (figura 1).

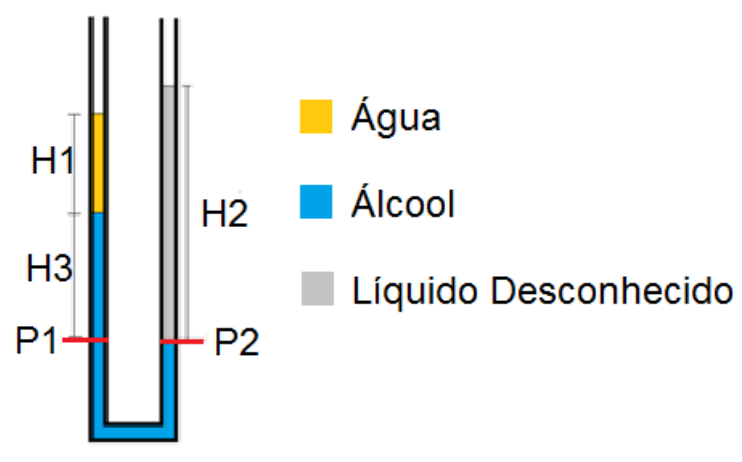

Figur

a 1 - Aparato experimental (Tubo em "u").

Quatro alunos mediram a altura de cada coluna de líquido, disponível na Tabela 1.

Tabela 1 - Altura das colunas de líquido.

\begin{tabular}{|c|c|c|c|c|}
\hline & $\mathrm{H} 1$ & $\mathrm{H} 2$ & $\mathrm{H} 3$ & Densidade \\
\hline Pessoa 1 & $0,219 \mathrm{~m}$ & $0,567 \mathrm{~m}$ & $0,250 \mathrm{~m}$ & $0,750 \mathrm{~kg} / \mathrm{m}^{3}$ \\
\hline Pessoa 2 & $0,219 \mathrm{~m}$ & $0,563 \mathrm{~m}$ & $0,254 \mathrm{~m}$ & $0,762 \mathrm{~kg} / \mathrm{m}^{3}$ \\
\hline Pessoa 3 & $0,200 \mathrm{~m}$ & $0,559 \mathrm{~m}$ & $0,254 \mathrm{~m}$ & $0,733 \mathrm{~kg} / \mathrm{m}^{3}$ \\
\hline Pessoa 4 & $0,220 \mathrm{~m}$ & $0,557 \mathrm{~m}$ & $0,248 \mathrm{~m}$ & $0,761 \mathrm{~kg} / \mathrm{m}^{3}$ \\
\hline
\end{tabular}

A partir do teste $t$, verificou-se que a única densidade calculada com diferença significativa foi a 


\section{Blucher Proceedins \\ V Encontro Científico de Física Aplicada}

calculada pela pessoa 3. O simples fato de não aferir corretamente a altura de um líquido influenciou o resultado final do experimento.

\section{Experimento II}

O objetivo deste experimento foi observar 0 comportamento da viscosidade ao longo do tempo para a glicerina e o amido de milho diluído em água.

A glicerina foi analisada pelos autores, experientes no manuseio do equipamento. Já a análise do amido foi feita pelos alunos voluntários. Os resultados são apresentados nas Figuras 1 e 2.

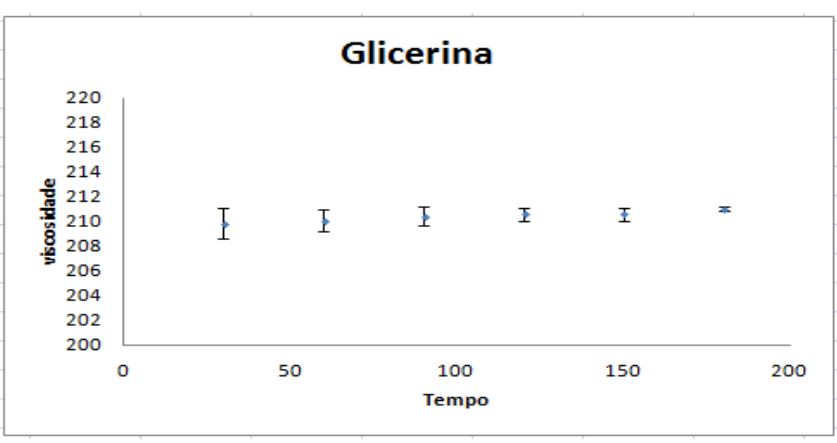

Figura 1 - Comportamento viscoso da glicerina.

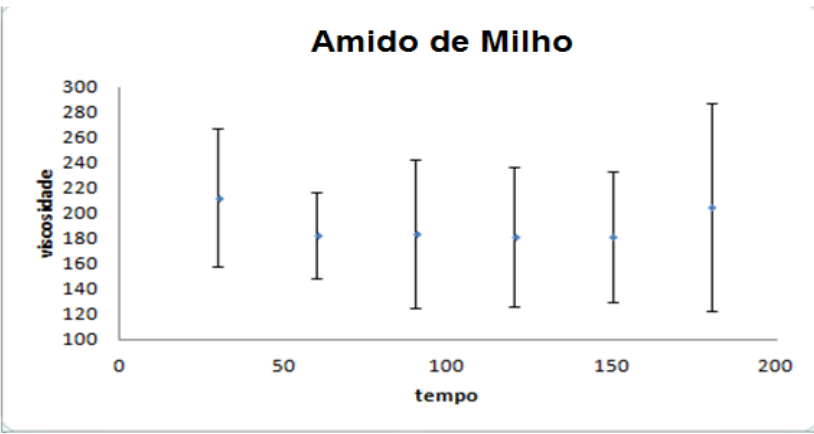

Figura 2 - Comportamento viscoso do amido.

A partir das análises em triplicata nota-se a importância de um profissional qualificado para utilização do equipamento a fim de reduzir os erros experimentais. Além disso, se os experimentos não fossem realizados em triplicata, poderiase considerar que a viscosidade do amido varia com o tempo. Entretanto, estatisticamente os resultados são equivalentes.

\section{Experimento III}

Neste experimento desejava-se saber se havia diferença na precisão do equipamento estudado (balança analítica) causado pelo posicionamento do ítem a ser pesado em diferentes pontos do equipamento.

Tomou-se um objeto de massa desconhecida, colocou-se nos quatro cantos e no centro da balança e registrou-se a massa. O teste repetido por três alunos foram apresentados na Tabela 2.

Tabela 2. Massa verificada pela balança analítica.

\begin{tabular}{|c|c|c|c|c|c|}
\hline & Teste 1 & Teste 2 & Teste 3 & Média & Variância \\
\hline Ponto 1 & $2,176 \mathrm{~g}$ & $2,178 g$ & $2,175 \mathrm{~g}$ & $2,176 \mathrm{~g}$ & $1,67 \times 10^{-6} \mathrm{~g}$ \\
\hline Ponto 2 & $2,180 \mathrm{~g}$ & $2,175 g$ & $2,175 g$ & $2,177 \mathrm{~g}$ & $5,67 \times 10^{-6} \mathrm{~g}$ \\
\hline Ponto 3 & $2,176 \mathrm{~g}$ & $2,177 \mathrm{~g}$ & $2,175 \mathrm{~g}$ & $2,176 \mathrm{~g}$ & $6,67 \times 10^{-1} \mathrm{~g}$ \\
\hline Ponto 4 & $2.178 \mathrm{~g}$ & $2,177 \mathrm{~g}$ & $2,175 \mathrm{~g}$ & $2,177 \mathrm{~g}$ & $1,67 \times 10^{-6} \mathrm{~g}$ \\
\hline Ponto 5 & $2,177 \mathrm{~g}$ & $2,174 \mathrm{~g}$ & $2,177 \mathrm{~g}$ & $2,176 \mathrm{~g}$ & $2,00 \times 10^{-6} \mathrm{~g}$ \\
\hline
\end{tabular}

Realizando os testes $\mathrm{t}$ e $\mathrm{F}$, foi possível notar que os valores de massa encontrados para todos os pontos são estatisticamente equivalentes, com um nível de incerteza de apenas $1 \%$. Isso mostra que a balança analisada apresenta boa repetibilidade e reprodutibilidade dos resultados em qualquer ponto do prato da mesma.

\section{Conclusão}

Erros observacionais e na operação de equipamentos podem influenciar de maneira significativa no resultado final de uma análise laboratorial. Assim, o ensino sobre a avaliação e influência desses erros podem ser minimizados pelo ensino e treinamento prévio dos envolvidos para melhor execução dos experimentos.

\section{Agradecimentos}

Os autores agradecem a FAPES pelo apoio financeiro e aos alunos da Escola E. E. F. M. Aristeu Aguiar, B. M. ESPINOSO, I. G. DE ASSIS' M. A. DE OLIVEIRA, S. R. DE CASTRO, R. R. VIEIRA, pela realização dos experimentos.

\section{Referências}

[1] Importância da Estatística para o Processo de Conhecimento e Tomada de Decisão, Curitiba. <http://www.ipardes.gov.br/biblioteca/docs/NT_06_importa ncia_estatistica_tomada_decisao.pdf $>$. Acesso em 15/11/13.

[2] MORETTIN, P. A.; BUSSAB, W. O. Estatística Básica. São Paulo. $8^{a}$ ed. Editora Saraiva: 2013. 